Article

\title{
Lattice oxygen activation in transition metal doped ceria
}

\author{
Ya-Qiong Su, Long Zhang, Valery Muravev, Emiel J. M. Hensen * \\ Laboratory of Inorganic Materials \& Catalysis, Schuit Institute of Catalysis, Eindhoven University of Technology, P.0. Box 513, 5600 MB Eindhoven, \\ The Netherlands
}

\section{A R T I C L E I N F O}

\section{Article history:}

Received 28 June 2019

Accepted 22 July 2019

Published 5 June 2020

\section{Keywords:}

Lattice oxygen activation

TM-doped $\mathrm{CeO}_{2}$ (111)

Density functional theory calculations

Oxygen vacancy

Square-planar coordination

Coordination transformation

CO oxidation

\begin{abstract}
A B S T R A C T
Density functional theory calculations were carried out to investigate the influence of doping transition metal (TM) ions into the ceria surface on the activation of surface lattice oxygen atoms. For this purpose, the structure and stability of the most stable (111) surface termination of $\mathrm{CeO}_{2}$ modified by TM ions was determined. Except for Zr and Pt dopants that preserve octahedral oxygen coordination, the TM dopants prefer a square-planar coordination when substituting the surface Ce ions. The surface construction from octahedral to square-planar is facile for all TM dopants, except for Pt (1.14 eV) and $\mathrm{Zr}$ (square-planar coordination unstable). Typically, the ionic radius of tetravalent TM cations is much smaller than that of $\mathrm{Ce}^{4+}$, resulting a significant tensile-strained lattice and explaining the lowered oxygen vacancy formation energy. Except for $\mathrm{Zr}$, the square-planar structure is the preferred one when one oxygen vacancy is created. Thermodynamic analysis shows that TM-doped $\mathrm{CeO}_{2}$ surfaces contain oxygen defects under typical conditions of environmental catalysis. A case of practical importance is the facile lattice oxygen activation in $\mathrm{Zr}$-doped $\mathrm{CeO}_{2}$ (111), which benefits $\mathrm{CO}$ oxidation. The findings emphasize the origin of lattice oxygen activation and the preferred location of TM dopants in TM-ceria solid solution catalysts.
\end{abstract}

(C) 2020, Dalian Institute of Chemical Physics, Chinese Academy of Sciences. Published by Elsevier B.V. All rights reserved.

\section{Introduction}

Ceria is extensively used as a support material in catalysis because of its high oxygen storage capacity [1]. In combination with transition metals, it can catalyze a large number of reactions, such as the water-gas shift reaction [2], $\mathrm{CO}_{2}$ reduction [3], NO reduction [4], $\mathrm{CH}_{4}$ combustion [5] and $\mathrm{CO}$ oxidation [6]. Besides the availability of lattice oxygen atoms of the support, the strong interaction of metals with ceria can boost the catalytic activity due to electron transfer. These effects are especially prominent for small particles [7-9]. In the extreme case, a catalyst can be made up of single atoms of a catalytically active transition metal (TM) supported on ceria. Such single-atom catalysts (SACs) present a new frontier in heterogeneous catalysis research with the potential of extremely high TM utilization due to the highly under-coordinated nature of the isolated metal atoms [10-12]. In addition, the support may also play an important role in the catalytic cycle by providing specific functionalities. As such, there is an analogy between SACs and non-innocent ligands in homogeneous catalysts $[13,14]$.

Generally, single metal atoms are more mobile on a support material than nanoparticles (NPs) and, therefore, SACs are prone to agglomeration [15-17]. Stabilization of single atoms by the support is therefore of critical importance to design stable SACs. Ceria can strongly interact with TMs, leading to a large metal-support interface $[18,19]$. These interactions are

\footnotetext{
* Corresponding author. Tel: +31-40-2475178; E-mail: e.j.m.hensen@tue.nl

This work was supported by The Netherlands Organization for Scientific Research (NWO) through a Vici grant and Nuffic funding. Access to supercomputing facilities was made possible by NWO. This work has also received funding from the European Union's Horizon 2020 research and innovation programme under grant No. 686086 (Partial-PGMs).

DOI: S1872-2067(19)63468-6 | http://www.sciencedirect.com/science/journal/18722067 | Chin. J. Catal., Vol. 41, No. 6, June 2020
} 
particularly strong between TM atoms and oxygen vacancies and step-edges. Another possibility is that TM cations substitute for Ce in the ceria lattice. Related to the latter, it has been found that substituting dopants into the ceria lattice can activate lattice oxygen, as most TM-O binding energies are lower than Ce-O binding energies in ceria [20,21]. The formation energy of oxygen vacancies $\left(\mathrm{V}_{0}\right)$ in $\mathrm{TM}$-doped $\mathrm{CeO}_{2}$ has been the topic of several theoretical investigations [22-26]. In all of these studies, a conventional structure of the TM dopant site has been adopted in which the octahedrally coordinated Ce ion is isomorphously substituted by a TM ion. Recently, we proposed another structure for Pd-doped $\mathrm{CeO}_{2}(111)$, in which the $\mathrm{Pd}$ atom adopts a square-plane configuration surrounded by four lattice oxygen atoms [27]. The removal of the lattice oxygen atom connected to $\mathrm{Pd}$ dopant requires a higher energy than that of the perfect $\mathrm{CeO}_{2}$ (111) surface, unlike the two-fold oxygen atoms that can be removed easily and generate oxygen vacancies. Therefore, it is necessary to thoroughly investigate the origination of the activated lattice oxygen in TM-doped $\mathrm{CeO}_{2}$.

In this study, we examine a series of TM-doped $\mathrm{CeO}_{2}$ (111) ( $\mathrm{TM}=\mathrm{Zn}, \mathrm{Cu}, \mathrm{Ni}, \mathrm{Co}, \mathrm{Fe}, \mathrm{Ag}, \mathrm{Pd}, \mathrm{Rh}, \mathrm{Zr}, \mathrm{Au}$, and Pt) by density functional theory (DFT) calculations to explore the most stable configurations and $\mathrm{V}_{0}$ formation energies. We also included $\mathrm{Zr}$ in this study as mixed cerium-zirconium oxides are extensively used in oxidation reactions, the isomorphous substitution in ceria resulting in a higher availability of lattice oxygen atoms and boosting reactions such as CO oxidation [28,29]. Given the size of $\mathrm{Zr}^{4+}$, isomorphous substitution for $\mathrm{Ce}^{4+}$ will lead to the retention of the octahedral coordination of the surface TM ion. In most of the other cases, doping ceria with TM ions leads to a structural transformation from an octahedral configuration around the TM dopant to a square planar one. For the most effective cation in terms of lattice oxygen activation (Zr), we explore catalytic $\mathrm{CO}$ oxidation.

\section{Computational details}

Spin-polarized calculations within the density-functional theory framework were carried out as implemented in the Vienna $a b$ initio simulation package (VASP) [30]. The ion-electron interactions were represented by the projector-augmented wave (PAW) method [31] and the electron exchange-correlation by the generalized gradient approximation (GGA) with the Perdew-Burke-Ernzerhof (PBE) exchange-correlation functional [32]. The Kohn-Sham valence states were expanded in a plane-wave basis set with a cut-off energy of $400 \mathrm{eV}$. The Ce $(5 s, 5 p, 6 s, 4 f, 5 d), \mathrm{O}(2 s, 2 p)$ and C $(2 s$, $2 p$ ) electrons were treated as valence states. The DFT $+U$ approach was used, in which $U$ is a Hubbard-like term describing the on-site Coulombic interactions [33]. This approach improves the description of localized states in ceria, where standard LDA and GGA functionals fail. For Ce, a value of $U=4.5 \mathrm{eV}$ was adopted, which was calculated self-consistently by Fabris et al. [34] using the linear response approach of Cococcioni and de Gironcoli [35] and which is within the 3.0-6.0 eV range that provides localization of the electrons left upon oxygen removal from ceria [36]. To model TM-doped $\mathrm{CeO}_{2}$ (111), we used a periodic ceria slab with a $(4 \times 4)$ surface unit cell. For Brillouin zone integration, a $1 \times 1 \times 1$ Monkhorst-Pack mesh was used. The bulk $\mathrm{CeO}_{2}$ equilibrium lattice constant (5.49 ̊) previously calculated by $\mathrm{PBE}+U(U=4.5 \mathrm{eV})$ was used [37]. The $\mathrm{CeO}_{2}(111)$ slab model is three Ce-O-Ce layers thick and the vacuum gap was set to $15 \AA$. The atoms in the bottom layer were frozen to their bulk position and the top two Ce-O-Ce layers were allowed to relax. The climbing image nudged-elastic band (CI-NEB) algorithm [38,39] was used to identify the transition states in the elementary reaction steps of structural transformation and CO oxidation. A frequency analysis was performed to confirm that each transition state has only a single imaginary frequency in the direction of the reaction coordinate. The total energy difference was less than $10^{-4} \mathrm{eV}$ and the relaxation convergence criterion was set at $0.05 \mathrm{eV} / \AA$.

The TM dopants in $\mathrm{CeO}_{2}$ (111) adopt octahedral and square-planar coordination, which are referred to as TM-dop-I and TM-dop-II, respectively. The creation of an oxygen vacancy thorugh the removal of a lattice oxygen atom results in structures denoted by TM-dop-I-Vo1 and TM-dop-II-V01, respectively. The formation energies of the first oxygen vacancy are defined as:

$$
\begin{aligned}
& E\left(\mathrm{I}-\mathrm{V}_{01}\right)=1 / 2 E\left(\mathrm{O}_{2}\right)+E\left(\mathrm{TM}-\text { dop-I-V }-\mathrm{V}_{01}\right)-E(\mathrm{TM}-\text { dop-I }) \\
& E\left(\mathrm{II}-\mathrm{V}_{01}\right)=1 / 2 E\left(\mathrm{O}_{2}\right)+E(\mathrm{TM}-\text { dop-II-V } \\
& 01)-E(\mathrm{TM}-\text { dop-II })
\end{aligned}
$$

Similarly, the formation energies of the second and third oxygen vacancies (only considered for square-planar coordination) are defined as:

$E\left(\mathrm{~V}_{02}\right)=1 / 2 E\left(\mathrm{O}_{2}\right)+E\left(\mathrm{TM}-\right.$ dop-II- $\left.\mathrm{V}_{02}\right)-E\left(\mathrm{TM}-\right.$ dop-II-V $\left.\mathrm{V}_{01}\right)$

$E\left(\mathrm{~V}_{03}\right)=1 / 2 E\left(\mathrm{O}_{2}\right)+E\left(\mathrm{TM}\right.$-dop- II- $\left.\mathrm{V}_{03}\right)-E\left(\mathrm{TM}\right.$-dop-II- $\left.\mathrm{V}_{02}\right)(4)$ in which $E\left(\mathrm{O}_{2}\right)$ is the energy of $\mathrm{O}_{2}$ in the gas phase, approximated by the computed electronic energy. E(TM-dop-I) and $E$ (TM-dop-II) are the electronic energies of TM-dop-I and TM-dop-II, respectively, $E$ (TM-dop-I-V $\mathrm{V}_{01}$ ) and $E$ (TM-dop-II-V the electronic energies of TM-dop-I- $\mathrm{V}_{01}$ and TM-dop-II- $\mathrm{V}_{01}$, respectively and $E$ (TM-dop-II-Vo2) and $E\left(\mathrm{TM}-\mathrm{dop}-\mathrm{II}-\mathrm{V}_{\mathrm{O}}\right)$ the electronic energies of TM-dop-II- $\mathrm{V}_{02}$ and TM-dop-II- $\mathrm{V}_{03}$, respectively.

The relative thermodynamic stability between TM-dop-I and TM-dop-II is defined as:

$$
\Delta E(\mathrm{I}-\mathrm{II})=E(\mathrm{TM}-\mathrm{dop}-\mathrm{II})-E(\mathrm{TM}-\mathrm{dop}-\mathrm{I})
$$

Similarly, the relative thermodynamic stability between TM-dop-I- $\mathrm{V}_{01}$ and TM-dop-II- $\mathrm{V}_{01}$ is defined as:

$$
\Delta E\left(\mathrm{~V}_{01}(\mathrm{I}-\mathrm{II})\right)=E\left(\mathrm{II}-\mathrm{V}_{01}\right)-E\left(\mathrm{I}-\mathrm{V}_{01}\right)
$$

We used the $a b$ initio thermodynamics approach of Reuter and Scheffler to assess the relative stability of various TM-doped states in ceira as a function of oxygen pressure and temperature[40]. The free energy of TM-doped surface states cn then be obtained by:

$$
\begin{gathered}
\Delta G=\Delta E+\frac{\mathrm{n}}{2} \mu_{O_{2}}(T, P) \\
=\left(E_{T M-d o p-V_{0 \mathrm{n}}}+\frac{\mathrm{n}}{2} E_{O_{2}}-E_{T M-d o p}\right)+\frac{\mathrm{n}}{2} \mu_{O_{2}}(T, P)
\end{gathered}
$$

where $E_{T M-d o p}$ and $E_{T M-d o p-V 0 n}$ are the electronic ground state energies of the TM-doped $\mathrm{CeO}_{2}(111)$ and its defective surface after removing $n$ oxygen atoms, respectively, $E_{02}$ the electronic ground state energy of gaseous $\mathrm{O}_{2}$, and $\mu_{02}(T, P)$ the chemical 


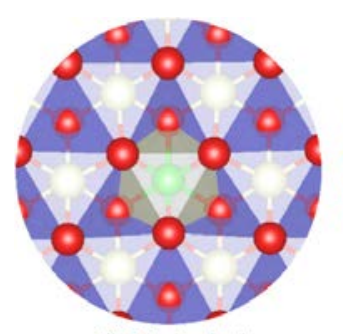

(I) Octahedral

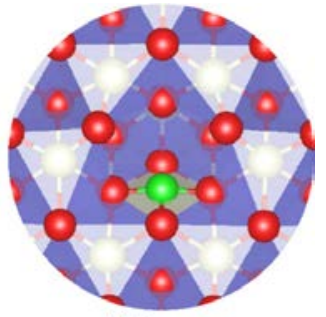

(II) Square
Fig. 1. Configurations of a single TM atom doped in to $\mathrm{CeO}_{2}(111)$ surface, (left) the octahedral configuration obtained by isomorphous substitution and (right) a square-planar contribution (color code: white, Ce red, 0; green, TM).

potential of gaseous $\mathrm{O}_{2}$. The chemical potential of gaseous oxygen can be correlated to the thermodynamic state in the following manner:

$$
\begin{gathered}
\mu_{O_{2}}(T, P)=\mu_{O_{2}}\left(T, P^{\theta}\right)+R T \ln \left(\frac{P_{O_{2}}}{P^{\theta}}\right) \\
=\left[H_{O_{2}}\left(T, P^{\theta}\right)-H_{O_{2}}\left(0 K, P^{\theta}\right)\right]-\mathrm{T}\left[S_{O_{2}}\left(T, P^{\theta}\right)-S_{O_{2}}\left(0 K, P^{\theta}\right)\right]+R T \ln \left(\frac{P_{O_{2}}}{P^{\theta}}\right)
\end{gathered}
$$

where the enthalpy $H_{02}\left(T, P^{\theta}\right)$ and entropy $S_{02}\left(T, P^{\theta}\right)$ of gaseous $\mathrm{O}_{2}$ were obtained from the standard thermodynamic tables [41]. The entropy of the solids is neglected.

\section{Results and discussion}

\subsection{Stability TM-doped $\mathrm{CeO}_{2}$}

TM-doped $\mathrm{CeO}_{2}$ is extensively used as heterogeneous catalysts due to their high activity and stability in a wide range of reactions [29,42]. Earlier, a number of theoretical studies have verified that doping TM atoms into octahedral Ce locations in the surface of $\mathrm{CeO}_{2}(111)$ is thermodynamically favorable [25,27,43]. Fig. 1 shows the octahedral and square-planar coordination environments of TM doped into the $\mathrm{CeO}_{2}$ (111) surface. Alternative to this conventionally considered configuration (TM-dop-I), we also explored the square-planar configuration (TM-dop-II). This TM-dop-II configuration has been earlier considered by us for Pd [27]. In TM-dop-II, two lattice oxygen atoms that were initially three-fold coordinated in $\mathrm{CeO}_{2}(111)$ and TM-dop-I become two-fold coordinated.

For Zn, Pd, Pt and Rh, the two considered configurations show nearly similar stability, as follows from Table 1 . For $\mathrm{Cu}$, $\mathrm{Ag}, \mathrm{Au}, \mathrm{Ni}, \mathrm{Co}$ and Fe, the square-planar TM-dop-II configuration is thermodynamically favored over the octahedral
TM-dop-I one. The exception is Zr for which Zr-dop-I is so strongly preferred that an initial Zr-dop-II spontaneously reverted to the octahedral configuration.

In a previous work [27], we showed that the activation energy barrier for the transformation from Pd-dop-I to Pd-dop-II is $0.53 \mathrm{eV}$, suggesting that under typical catalytic conditions this transformation can easily occur. We explored in this study the activation barriers for the similar transformation of other TM dopants in the ceria surface (Table 1). For $\mathrm{Zn}, \mathrm{Rh}, \mathrm{Ag}, \mathrm{Au}$ and $\mathrm{Ni}$, the transformation requires overcoming relatively low activation barriers of $0.27,0.32,0.32,0.63$ and $0.22 \mathrm{eV}$, respectively. The activation barriers are negligible for $\mathrm{Cu}$, Co, and $\mathrm{Fe}$. On the other hand, the barrier is significantly higher for Pt at $1.14 \mathrm{eV}$. This can well explain the experimentally observed preference for $\mathrm{Pt}^{4+}$ substitutions in Pt-ceria solid solutions [44-46]. The Pt oxidation states in Pt-dop-I and Pt-dop-II are $4+$ and 2+, respectively.

The typical preference for TM-dop-II is related to the smaller size of the $\mathrm{TM}^{4+}$ ions $\mathrm{Ni}, \mathrm{Pd}, \mathrm{Pt}, \mathrm{Rh}$, the $\mathrm{TM}^{3+}$ ions $\mathrm{Cu}, \mathrm{Au}, \mathrm{Co}$, Fe and the $\mathrm{Zn}^{2+}$ ion in TM-dop-I with respect to the $\mathrm{Ce}^{4+}$ ion [5]. This is confirmed by the data in Table 2 . Only $\mathrm{Zr}^{4+}(0.86 \AA)$ has a comparable ionic radius as $\mathrm{Ce}^{4+}(0.97 \AA)$ and, therefore, prefers the octahedral configuration. Especially, $\mathrm{Ni}^{4+}$ has a small ionic radii of $0.48 \AA$. The substitution of TM cations with a small ionic radius results in a weak bonding between the TM ion and lattice $\mathrm{O}$ atoms in TM-dop-I. The $\mathrm{Ce}^{4+-} \mathrm{O}$ bond length in $\mathrm{CeO}_{2}(111)$ surface is $2.37 \AA$. Direct isomorphous substitution by $\mathrm{TM}$ atoms results in a tensile-strained lattice. Although $\mathrm{Ag}^{3+}$ has a large ionic radii of $1.26 \AA$, the resulting Ag-O bonds in Ag-dop-I are 2.15 and $2.18 \AA$, much smaller than Ce-O bond length. In TM-dop-II, TM atoms are generally in the +2 or +3 oxidation state and coordinated by four lattice 0 atoms, with TM-O bond lengths in the 1.9-2.0 $\AA$ range. These results indicate that the TM-dop-II configuration can provide a more suitable coordination environment for TM dopants, except for Zr.

\subsection{Oxygen vacancy formation}

The formation energy of oxygen vacancies provides an indication of the surface reactivity upon substitution of Ce by TM. The direct removal of one oxygen atom from TM-dop-I results in a configuration in which the TM atom is coordinated by two oxygen atoms in the top surface layer and two oxygen in the subsurface layer, as shown in Fig. 2. The removal of one oxygen atom from TM-dop-II results in a configuration in which the TM

Table 1

\begin{tabular}{|c|c|c|c|c|c|c|c|c|c|c|c|}
\hline TM elements & $\mathrm{Cu}$ & $\mathrm{Ag}$ & $\mathrm{Au}$ & $\mathrm{Ni}$ & $\mathrm{Pd}$ & $\mathrm{Pt}$ & Co & $\mathrm{Rh}$ & $\mathrm{Fe}$ & $\mathrm{Zr}$ & $\mathrm{Zn}$ \\
\hline$\overline{\Delta E(\mathrm{I}-\mathrm{II})}$ & $\begin{array}{l}-1.52 \\
\end{array}$ & -0.55 & -0.60 & -1.41 & 0.01 & 0.02 & -1.57 & -0.03 & -0.23 & - & -0.01 \\
\hline$E_{\mathrm{a}}(\mathrm{I}-\mathrm{II})$ & 0.09 & 0.32 & 0.63 & 0.22 & 0.53 & 1.14 & 0 & 0.32 & 0.03 & - & 0.27 \\
\hline$E\left(\mathrm{I}-\mathrm{V}_{01}\right)$ & -0.22 & -0.25 & 0.27 & -1.56 & 0.84 & 1.60 & -0.63 & 1.32 & 0.98 & 1.56 & -0.90 \\
\hline$E\left(\mathrm{II}-\mathrm{V}_{01}\right)$ & 0.05 & 0.08 & 0.08 & -0.16 & -0.57 & -0.01 & 0.03 & 0.75 & 0.69 & - & -0.83 \\
\hline$\Delta E\left(\mathrm{~V}_{01}(\mathrm{I}-\mathrm{II})\right)$ & -1.24 & -0.22 & -0.80 & - & -1.40 & -1.59 & -0.92 & -0.91 & -0.52 & - & 0.06 \\
\hline$E_{\mathrm{a}}\left(\mathrm{V}_{01}(\mathrm{I}-\mathrm{II})\right)$ & 0 & 0.01 & 0.48 & 0 & 0.07 & 0.37 & 0.28 & 0.12 & 0.40 & - & 0.13 \\
\hline$E\left(\mathrm{~V}_{02}\right)$ & 1.21 & 1.35 & 1.24 & 1.24 & 1.09 & 1.23 & 1.27 & 1.32 & 1.21 & 1.54 & 1.34 \\
\hline$E\left(\mathrm{~V}_{03}\right)$ & 1.70 & 1.24 & 1.69 & 2.57 & 2.87 & 3.11 & 2.33 & 3.02 & 1.76 & 2.30 & 1.21 \\
\hline
\end{tabular}

Thermodynamic and kinetic properties of TM-doped $\mathrm{CeO}_{2}(111)$ (all energies in eV).

$E_{\mathrm{a}}$ is the energy barrier associated with the transformation from TM-dop-I to TM-dop-II and from $\mathrm{TM}^{-d o p}$-I-VO $\mathrm{V}_{1}$ to $\mathrm{TM}^{-}$-dop-II-VO ${ }_{1}$, respectively. 
Table 2

Ionic radii of various TM cations (in $\AA$ ).

\begin{tabular}{|c|c|c|c|c|c|c|c|c|c|c|c|c|}
\hline TM elements & $\mathrm{Ce}$ & $\mathrm{Cu}$ & $\mathrm{Ag}$ & $\mathrm{Au}$ & $\mathrm{Ni}$ & $\mathrm{Pd}$ & $\mathrm{Pt}$ & Co & $\mathrm{Rh}$ & $\mathrm{Fe}$ & $\mathrm{Zr}$ & $\mathrm{Zn}$ \\
\hline $4+$ & 0.97 & - & - & - & 0.48 & 0.63 & 0.62 & 0.53 & 0.62 & 0.59 & 0.86 & - \\
\hline $3+$ & 1.04 & 0.54 & 1.26 & 0.85 & 0.60 & 0.70 & 0.75 & 0.65 & 0.67 & 0.67 & 0.89 & - \\
\hline $2+$ & - & 0.73 & - & - & 0.69 & 0.64 & 0.80 & 0.78 & 0.72 & 0.78 & - & 0.74 \\
\hline+ & - & 0.46 & 1.02 & 1.37 & - & - & - & - & - & - & - & - \\
\hline
\end{tabular}

Data from literature [5,47-53].

atom keeps the same coordination. We name these configurations, TM-dop-I- $\mathrm{V}_{01}$ and TM-dop-II- $\mathrm{V}_{01}$, respectively. Table 1 lists the corresponding $\mathrm{V}_{0}$ formation energies. The $\mathrm{V}_{0}$ formation energy of the clean $\mathrm{CeO}_{2}(111)$ surface is $2.38 \mathrm{eV}$, in comparison to $1 / 2 \mathrm{O}_{2}$ in the gas phase [54]. The $\mathrm{V}_{0}$ formation energies of Pt-dop-I, Zr-dop-I, Rh-dop-I, Fe-dop-I and Pd-dop-I are considerably lower than this value. While the value for $\mathrm{Au}$-dop-I is much lower at $0.27 \mathrm{eV}$, the $\mathrm{V}_{0}$ formation process is exothermic for $\mathrm{Zn}$-, Cu-, Ag-, Ni- and Co-dop-I. On the other hand, for nearly all TM the $\mathrm{V}_{0}$ formation energies for TM-dop-II are negligible, for Rh-dop-II and Fe-dop-II with values of 0.75 and $0.68 \mathrm{eV}$, respectively. Moreover, we note that the TM-dop-II-V01 configuration is more stable than the TM-dop-I-V $\mathrm{V}_{01}$ for most of the TM. We earlier computed activation barriers of 0.07 and $0.39 \mathrm{eV}$ for Pd and Pt, respectively, for the transformation of TM-dop-I-V01 to TM-dop-II-V01 [27]. For the other TM, the activation barriers for this transformation are also very small (Table 1). For Ni, the TM-dop-I-V01 spontaneously relax to the corresponding TM-dop-II-V01 configuration, after removing one surface oxygen atom from the stoichiometric structures. These findings demonstrate that the TM-dop-I-V $V_{01}$ structures are unstable and will easily transform into TM-dop-II-Vo1.

We also computed the energy cost for the formation of the second and third oxygen vacancy (TM-dop-V02 and TM-dop- $\mathrm{V}_{03}$ ) for the TM-dop-II structure. We limited ourselves to these structures, as TM-dop-II- $\mathrm{V}_{01}$ is thermodynamically favored over TM-dop-I-Vo1, except for Zr. TM-dop-Vo2 is preferentially obtained by removing another two-fold lattice oxygen atom, while TM-dop- $\mathrm{V}_{03}$ is obtained by removing the lattice oxygen atom connected to the TM dopant. It is worthwhile to mention that $\mathrm{Zr}$-dop- $\mathrm{VO}_{2}$ and $\mathrm{Zr}$-dop- $\mathrm{VO}_{2}$ are obtained by suc-
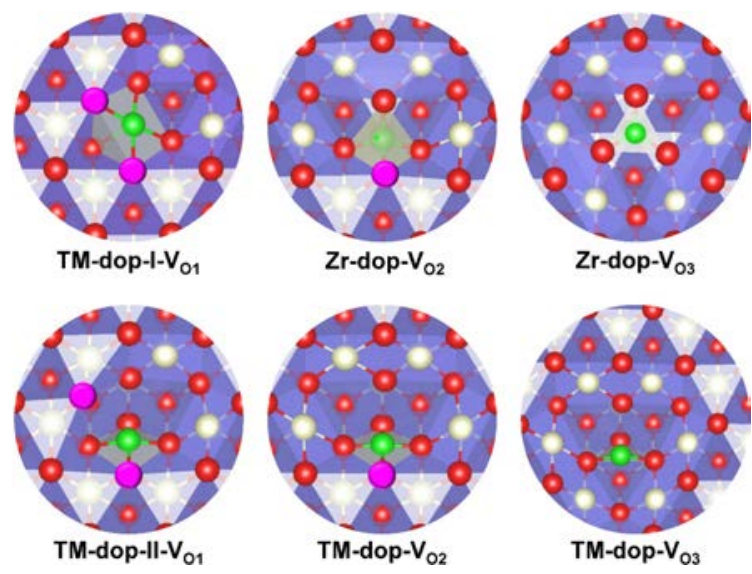

Fig. 2. Various oxygen vacancies for models I and II (color code: white, Ce; red, 0; green, TM; pink, top-surface 0 connected to TM). cessively removing lattice oxygen atoms connected to $\mathrm{Zr}$ in $\mathrm{Zr}$-dop-I- $\mathrm{VO}_{1}$, as shown in Fig. 2. The TM-dop- $\mathrm{V}_{02}$ formation energies are typically between 1.09 and $1.35 \mathrm{eV}$, although it is higher for $\mathrm{Zr}(1.54 \mathrm{eV})$. The chemical potentials of gaseous $\mathrm{O}_{2}$ are circa $0.55,0.77$ and $0.99 \mathrm{eV}$ at $P_{02}=1 \mathrm{~atm}$ and $T=300,400$ and $500 \mathrm{~K}$, respectively. Compared to these values, we can conclude that the second two-fold lattice oxygen atom is thermodynamically stable under reaction conditions relevant to catalysis. Therefore, we expect that only a single oxygen vacancy will be obtained under typical conditions. Notably, the $\mathrm{TM}-\mathrm{dop}-\mathrm{V}_{03}$ formation process involves large energy penalties for $\mathrm{Ni}, \mathrm{Pd}, \mathrm{Pt}$ and $\mathrm{Rh}$. The energy costs of $\mathrm{TM}-\mathrm{dop}-\mathrm{V}_{03}$ formation for $\mathrm{Co}$ and $\mathrm{Zr}$ are both $2.33 \mathrm{eV}$. For $\mathrm{Zn}, \mathrm{Cu}, \mathrm{Ag}$, $\mathrm{Au}$ and $\mathrm{Fe}$, the $\mathrm{V}_{03}$ formation energies are 1.21, 1.70, 1.24, 1.69 and $1.76 \mathrm{eV}$, respectively. The results demonstrate that $\mathrm{Cu}, \mathrm{Ag}, \mathrm{Au}$ and $\mathrm{Fe}$ can substantially activate the lattice $\mathrm{O}$ atoms connected to them. Co and $\mathrm{Zr}$ can also slightly activate the lattice $\mathrm{O}$ atoms, compared to the lattice $\mathrm{O}$ atoms of the clean $\mathrm{CeO}_{2}$ (111) surface. $\mathrm{Ni}, \mathrm{Pd}, \mathrm{Pt}$ and $\mathrm{Rh}$ suppress the reactivity of lattice $\mathrm{O}$ atoms.

Given the size of the relatively small TM cations in comparison to $\mathrm{Ce}^{4+}$, it is also possible to replace one Ce cation with two TM cations [5]. One of the TM cations is exposed to the medium and can, therefore, be involved in adsorption and catalysis. In the optimized model, the additional TM atom binds to the TM dopant via the two-fold coordinated oxygen atoms. These oxygen atoms dictate the catalytic reactivity. Moreover, these doped TM cations present a very stable configuration and we earlier speculated that such sites can also act as nucleation center for supported TM nanoparticles. There are strong experimental indications for the importance of the combination of TM dopants with TM nanoparticles [55-57]. In this configuration, dopants such as $\mathrm{Ni}, \mathrm{Pd}, \mathrm{Pt}$ and $\mathrm{Rh}$ cannot activate lattice $\mathrm{O}$ atoms, while $\mathrm{Cu}, \mathrm{Ag}$, $\mathrm{Au}$ and $\mathrm{Fe}$ can effectively activate lattice 0 atoms.

\subsection{Phase diagrams}

We determined the formal oxidation state by counting the total number of excess electrons localized in empty $\mathrm{Ce}$ 4 -orbital, which is related to the formation of $\mathrm{Ce}^{3+}$ ions. For example, in Au-dop-II- $\mathrm{V}_{01}$ and $\mathrm{Au}-\mathrm{dop}-\mathrm{V}_{03}$, one and three $\mathrm{Ce}^{3+}$ ions, respectively, are present as shown in Fig. 3. Thus, $\mathrm{Au}$ is formally in the +3 and +1 oxidation state, respectively, in these two structures. Another way of approximating the charge on the TM dopants is by Bader charge analysis. Such analysis shows that $\mathrm{Au}$ in $\mathrm{Au}$-dop-I, Au-dop-II and Au-dop-II-Vo1 exhibits $+1.24,+1.13$ and +1.12 e oxidation states, respectively. The lower oxidation states derive from charge transfer from lattice 

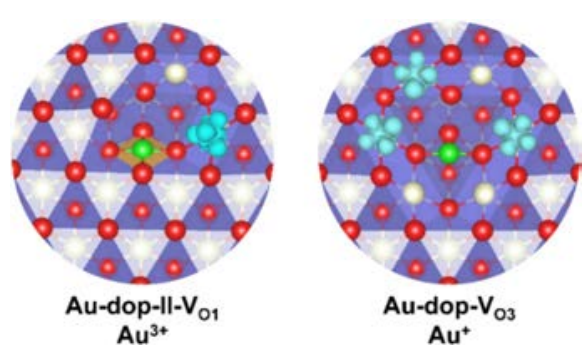

Fig. 3. Calculated iso-surfaces of the spin density in Au-dop-II- $V_{01}$ and $\mathrm{Au}$-dop- $\mathrm{V}_{03}$ (color code: white, $\mathrm{Ce}$; red, O; green, $\mathrm{Au}$ ).

$\mathrm{O}$ atoms, as confirmed by magnetic moments of lattice $\mathrm{O}$ atom in the Au-dop-I and Au-dop-II models of $0.67 \mu_{\mathrm{B}}$ and $0.83 \mu_{\mathrm{B}}$, respectively. In Au-dop-II-Vo1, the magnetic moment of the other lattice $\mathrm{O}$ atoms are zero, while the magnetic moment of one of the Ce atoms is $0.99 \mu_{\mathrm{B}}$, consistent with the formation of one $\mathrm{Ce}^{3+}$. In Pt-dop-I, there are no excess electrons, implying that $\mathrm{Pt}$ remains formally in the +4 oxidation state, in agreement with experimental data [44-46]. On the other hand, for a $\mathrm{Pd}-\mathrm{CeO}_{2}$ solid solution, the dominant oxidation state is $\mathrm{Pd}^{2+}$ [58]. Our previous work demonstrated that the oxidation state of $\mathrm{Pd}$ atom in $\mathrm{Pd}$-dop-II is $\mathrm{Pd}^{2+}$, owing to the electron donation of lattice oxygen atoms [27]. In our model, this is consistent with the facile transformation from Pd-dop-I to Pd-dop-II and the subsequent removal of one of the oxygen atoms. $\mathrm{Zr}$ and $\mathrm{Pt}$ preserve the +4 oxidation state in solid solutions with $\mathrm{CeO}_{2}$, due to the kinetic limitation of structure transformation at room temperature. The other TM dopants prefer to adopt +2 and +3 oxidation states, after generating an oxygen vacancy.

Based on the computed oxygen vacancy formation energies, we constructed stability diagrams for several TM-doped $\mathrm{CeO}_{2}(111)$ surfaces $(\mathrm{TM}=\mathrm{Cu}, \mathrm{Au}$ and $\mathrm{Zr}$ ). These are phase diagrams in the thermodynamic sense by considering the free energy of the system. Fig. 4 shows that Cu-dop-II-V $V_{01}$ and $\mathrm{Au}$-dop-II-Vo1 are the dominant species under typical reaction conditions at relatively low temperature. On the other hand, the favorable structure is Zr-dop-I. It further verifies that the TM-dop-II- $\mathrm{V}_{01}$ is an important candidate structure of transition metal-ceria solid solution, which is thermodynamically relevant for the realistic catalytic conditions.

$\mathrm{Cu}-\mathrm{CeO}_{2}$ is one of the relevant systems for environmental catalysis such as $\mathrm{CO}$ oxidation $[59,60]$. In $\mathrm{Cu}-\mathrm{CeO}_{2}$ solid solutions, $\mathrm{Cu}$ ions mainly remain in the +2 and +3 oxidation state under oxygen-rich catalytic conditions $[59,61,62]$. In line with this, we computed that $\mathrm{Cu}$ in $\mathrm{Cu}-\mathrm{dop}-\mathrm{II}-\mathrm{V}_{01}$ has a close to +3 oxidation state. Adding more TM such as $\mathrm{Cu}$ results in a lower oxidation states, leading to the formation of $\mathrm{Cu}^{2+}$ and eventually $\mathrm{Cu}^{+}$[5]. Similarly, the $\mathrm{Au}$ dopant remains in the +3 oxidation state in accordance with experimental observation [63]. On the other hand, Zr maintains the +4 oxidation state $[64,65]$.

\subsection{CO oxidation by $\mathrm{Zr}$-doped $\mathrm{CeO}_{2}$ (111)}

Given the importance of ceria-zirconia solid solutions, we also explored how activation of lattice oxygen by $\mathrm{Zr}$ insertion into $\mathrm{CeO}_{2}$ (111) affects $\mathrm{CO}$ oxidation. As outlined above, the $\mathrm{Zr}$ substitution remains in octahedral coordination after insertion in the surface. Due to the slightly smaller ionic radii of $\mathrm{Zr}^{4+}$ than $\mathrm{Ce}^{4+}$, the $\mathrm{V}_{0}$ formation energy is lowered in the doped structure. Therefore, $\mathrm{Zr}$ is an important substitution for Ce atoms to synthesize highly active ceria-based catalysts with a high oxygen storage capacity [66-68]. A catalytic cycle for CO oxidation is shown in Fig. 5.

$\mathrm{CO}$ adsorption on the $\mathrm{Zr}$ cation in $\mathrm{Zr}$-doped $\mathrm{CeO}_{2}(111)$ is weak $\left(E_{\text {ads }}=-0.51 \mathrm{eV}\right)$. Subsequent $\mathrm{CO}$ oxidation by one lattice 0 atom involves a negligible energy barrier $\left(E_{\mathrm{a}}=0.02 \mathrm{eV}\right)$. The following $\mathrm{CO}_{2}$ desorption step is facile $(\Delta E=0.43 \mathrm{eV})$. The resulting Zr-dop-I- $\mathrm{V}_{01}$ structure binds another $\mathrm{CO}$ with a slightly higher adsorption energy of $-0.70 \mathrm{eV}$. The next $\mathrm{CO}_{2}$ formation event requires overcoming an energy barrier of $0.29 \mathrm{eV}$ and is followed by an easy $\mathrm{CO}_{2}$ desorption $(\Delta E=0.14 \mathrm{eV})$. One $\mathrm{O}_{2}$ molecule strongly adsorbs on the resulting Zr-dop-I- $\mathrm{V}_{02}\left(E_{\mathrm{ads}}=\right.$ $-1.56 \mathrm{eV}$ ), and then is dissociated overcoming an energy barrier of $0.67 \mathrm{eV}$. This closes the catalytic cycle. For CO oxidation over pure $\mathrm{CeO}_{2}(111)$, $\mathrm{CO}$ adsorption is weaker $\left(E_{\mathrm{ads}}=-0.51\right.$ $\mathrm{eV}$ ), and the required energy barrier for the first $\mathrm{CO}_{2}$ formation step is $0.37 \mathrm{eV}$. The second CO adsorption energy is $-0.45 \mathrm{eV}$, and the subsequent $\mathrm{CO}_{2}$ formation overcomes an energy barrier of $0.31 \mathrm{eV}$. One $\mathrm{O}_{2}$ molecule strongly adsorbs on the resulting $V_{02}$ site $\left(E_{\text {ads }}=-2.35 \mathrm{eV}\right)$, and then oxygen dissociation requires an energy barrier of $0.82 \mathrm{eV}$. The $\mathrm{CO}_{2}$ desorption energy is slightly endothermic by 0.48 and $0.40 \mathrm{eV}$, respectively. Obviously, the introduction of $\mathrm{Zr}$ can improve the reactivity of surface lattice oxygen atoms of $\mathrm{CeO}_{2}$, owing to the lowered formation energy of oxygen vacancies. During the whole CO oxidation cycle, $\mathrm{CO}_{2}$ desorption is facile and the rate-limiting step is
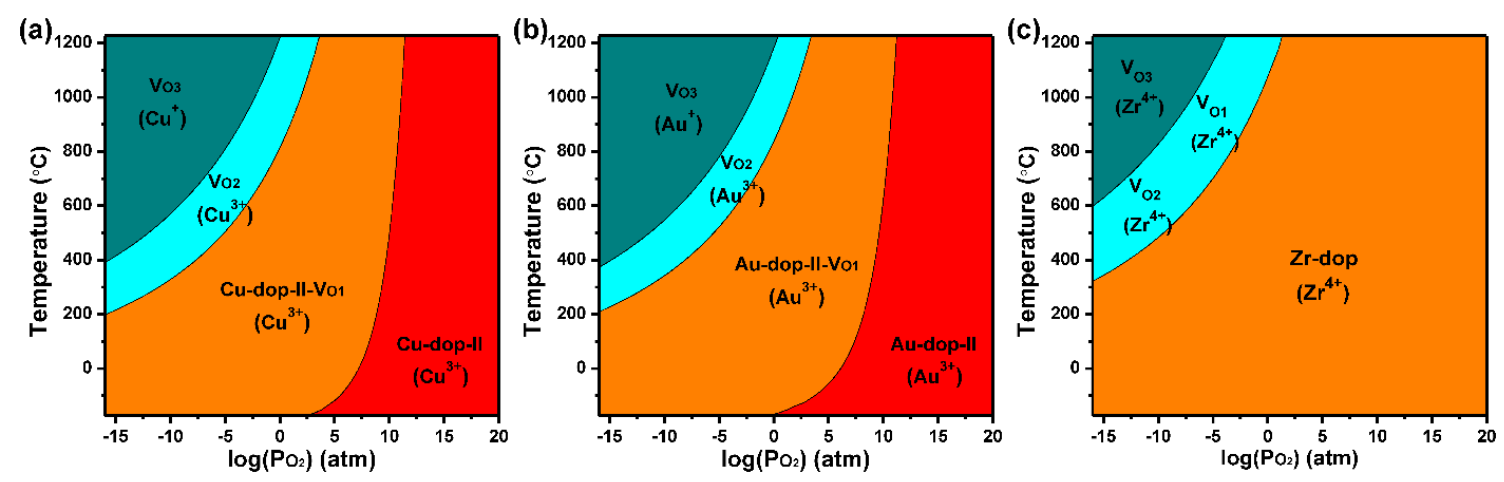

Fig. 4. Stability diagrams of $\mathrm{Cu}-, \mathrm{Au}$ - and $\mathrm{Zr}$-doped $\mathrm{CeO}_{2}(111)$ surfaces as a function of the temperature and the oxygen partial pressure based on an ab initio thermodynamic analysis using first-principles DFT data. 


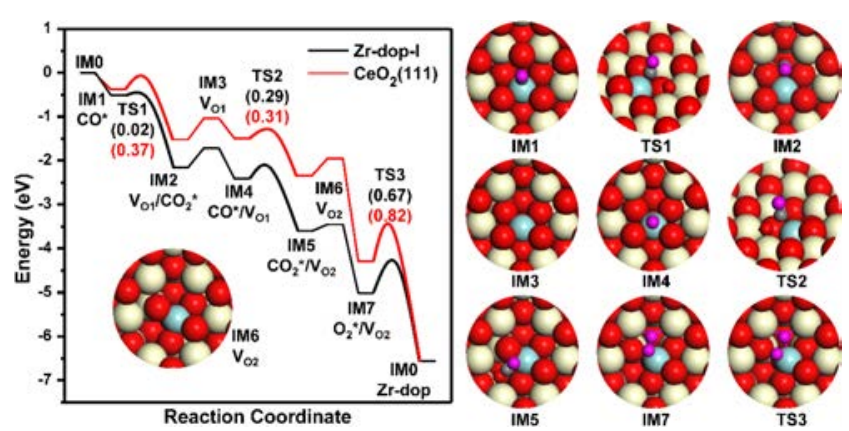

Fig. 5. Potential energy diagram of $\mathrm{CO}$ oxidation by $\mathrm{Zr}$-doped $\mathrm{CeO}_{2}(111)$ and pure $\mathrm{CeO}_{2}$ (111) (color code: white, Ce; red, O; cyan, Zr; gray, C; pink $\mathrm{O}$ of molecular $\mathrm{CO}$ and $\mathrm{O}_{2}$ ).

likely $\mathrm{O}_{2}$ dissociation. We note that the rate of this system will be low because of a low $\mathrm{CO}$ coverage. Previously, we explored $\mathrm{CO}$ oxidation by Pt-doped $\mathrm{CeO}_{2}$ (111) [43], where $\mathrm{CO}$ adsorption is strong $\left(E_{\mathrm{ads}}=-1.69 \mathrm{eV}\right)$ and the required energy barrier for $\mathrm{CO}_{2}$ formation is negligible. On the other hand, in this system $\mathrm{CO}_{2}$ desorption costs $1.61 \mathrm{eV}$, indicative of a limited activity at low temperature. In comparison, $\mathrm{CO}_{2}$ desorption costs $0.65 \mathrm{eV}$ from the Pd-doped $\mathrm{CeO}_{2}$ (111) surface [25]. The complete $\mathrm{CO}$ oxidation mechanism by Pt-dop-II- $V_{01}$ and Pd-dop-II- $V_{01}$ have been thoroughly investigated in our previous work [27,43]. The dopants in square-planar coordination exhibit a higher CO oxidation activity compared to the stoichiometric ceria surface. Although usually $\mathrm{Zr}$-doped $\mathrm{CeO}_{2}$ is used together with an active metal phase, presumably allowing for a stronger adsorption and therefore higher coverage of $\mathrm{CO}$, these data show that $\mathrm{Zr}$-doping can facilitate the availability of oxygen atom of the ceria surface.

\section{Conclusions}

We investigated the activation of lattice oxygen atoms in ceria by transition metal dopants. The doped metal atoms prefer to be square-planarly coordinated by four lattice 0 atoms over the conventional octahedral coordination, except for $\mathrm{Zr}$ and $\mathrm{Pt}$. While the transformation from Pt-dop-I to Pt-dop-II requires a high kinetic barrier, these transformations are facile for the other transition metals considered. The ionic radius of tetravalent TM cations is much smaller than that of $\mathrm{Ce}^{4+}$, resulting a significant tensile-strained ceria lattice and a decreased oxygen vacancy formation energy. Under typical conditions of low-temperature reactions in the context of environmental catalysis, the thermodynamically favorable species is TM-dop-II-Vo1 (except for $\mathrm{Zr}$ ), in which there is one oxygen vacancy and the TM atom adopts the square-planar coordination. $\mathrm{Zn}, \mathrm{Cu}, \mathrm{Ag}$, $\mathrm{Au}$ and $\mathrm{Fe}$ as dopants activate the lattice oxygen connected to them. $\mathrm{Zr}$ as a dopant preserves its octahedral coordination in ceria lattice due to the comparable ionic radii of $\mathrm{Zr}^{4+}$ and $\mathrm{Ce}^{4+}$. It leads to higher reactivity in a $\mathrm{CO}$ oxidation cycle in which $\mathrm{CO}$ adsorbs to a $\mathrm{Zr}$ surface cation followed by $\mathrm{CO}_{2}$ formation. Our work provides a detailed insight into the changed coordination of most transition metal dopants in the surface of ceria with respect to conventionally considered isomorphous substitution models. The high stability and reactivity of the explored single-atom configurations doped into the surface are also of topical interest in the framework of single-atom catalysis.

\section{References}

[1] C. Sun, H. Li, L. Chen, Energ. Environ. Sci., 2012, 5, 8475-8505.

\section{Graphical Abstract}

Chin. J. Catal., 2020, 41: 977-984 doi: S1872-2067(19)63468-6

\section{Lattice oxygen activation in transition metal doped ceria}

Ya-Qiong Su, Long Zhang, Valery Muravev, Emiel J. M. Hensen* Eindhoven University of Technology, the Netherlands
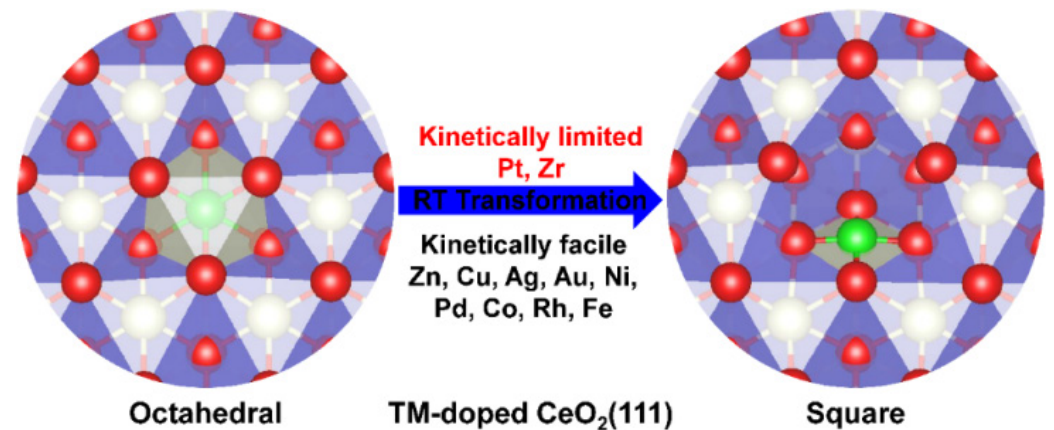

Isomorphous substitution of $\mathrm{Ce}$ cations in the $\mathrm{CeO}_{2}(111)$ surface by TM atoms results in a surface reconstruction to a square planar coordination and a tensile-strained lattice which account for the lowered oxygen vacancy formation energy. 
[2] Q. Fu, H. Saltsburg, M. Flytzani-Stephanopoulos, Science, 2003, 301, 935-938.

[3] J. Graciani, K. Mudiyanselage, F. Xu, A. E. Baber, J. Evans, S. D. Senanayake, D. J. Stacchiola, P. Liu, J. Hrbek, J. F. Sanz, Science, 2014, 345, 546-550.

[4] S. Li, N. Wang, Y. Yue, G. Wang, Z. Zu, Y. Zhang, Chem. Sci., 2015, 6, 2495-2500.

[5] Y. Q. Su, J. X. Liu, I. A. W. Filot, L. Zhang, E. J. M. Hensen, ACS Catal., 2018, 8, 6552-6559.

[6] J. Jones, H. Xiong, A. T. DeLaRiva, E. J. Peterson, H. Pham, S. R. Challa, G. Qi, S. Oh, M. H. Wiebenga, X. I. P. Hernández, Science, 2016, 353, 150-154.

[7] L. Liu, A. Corma, Chem. Rev., 2018, 118, 4981-5079.

[8] M. Nesselberger, M. Roefzaad, R. F. Hamou, P. U. Biedermann, F. F. Schweinberger, S. Kunz, K. Schloegl, G. K. Wiberg, S. Ashton, U. Heiz, Nature Mater., 2013, 12, 919-924.

[9] M. Turner, V. B. Golovko, O. P. Vaughan, P. Abdulkin, A. Berenguer-Murcia, M. S. Tikhov, B. F. Johnson, R. M. Lambert, Nature, 2008, 454, 981-983.

[10] A. Wang, J. Li, T. Zhang, Nature Rev. Chem., 2018, 2, 65-81.

[11] F. Dvořák, M. F. Camellone, A. Tovt, N. D. Tran, F. R. Negreiros, M. Vorokhta, T. Skála, I. Matolínová, J. Mysliveček, V. Matolín, Nature Comm., 2016, 7, 10801.

[12] X. F. Yang, A. Wang, B. Qiao, J. Li, J. Liu, T. Zhang, Acc. Chem. Res., 2013, 46, 1740-1748.

[13] H. Grützmacher, Angew. Chem. Int. Ed., 2008, 47, 1814-1818.

[14] J. L. Boyer, J. Rochford, M. K. Tsai, J. T. Muckerman, E. Fujita, Coordin. Chem. Rev., 2010, 254, 309-330.

[15] Y. Q. Su, J. X. Liu, I. A. W. Filot, E. J. M. Hensen, Chem. Mater., 2017, 29, 9456-9462.

[16] F. R. Negreiros, S. Fabris, J. Phys. Chem. C, 2014, 118, 21014-21020.

[17] T. W. Hansen, A. T. DeLaRiva, S. R. Challa, A. K. Datye, Acc. Chem. Res., 2013, 46, 1720-1730.

[18] M. Cargnello, J. D. Jaén, J. H. Garrido, K. Bakhmutsky, T. Montini, J. C. Gámez, R. Gorte, P. Fornasiero, Science, 2012, 337, 713-717.

[19] A. Bruix, J. A. Rodriguez, P. J. Ramírez, S. D. Senanayake, J. Evans, J. B. Park, D. Stacchiola, P. Liu, J. Hrbek, F. Illas, J. Am. Chem. Soc., 2012, 134, 8968-8974.

[20] L. Zhou, X. Li, Z. Yao, Z. Chen, M. Hong, R. Zhu, Y. Liang, J. Zhao, Sci. Rep., 2016, 6, 23900.

[21] Z. Hu, B. Li, X. Sun, H. Metiu, J. Phys. Chem. C, 2011, 115, 3065-3074.

[22] W. Tang, Z. Hu, M. Wang, G. D. Stucky, H. Metiu, E. W. McFarland, J. Catal., 2010, 273, 125-137.

[23] A. D. Mayernick, M. J. Janik, J. Catal., 2011, 278, 16-25.

[24] A. D. Mayernick, M. J. Janik, J. Phys. Chem. C, 2008, 112, 14955-14964.

[25] W. C. Ding, X. K. Gu, H. Y. Su, W. X. Li, J. Phys. Chem. C, 2014, 118, 12216-12223.

[26] Y. Tang, Y. G. Wang, J. Li, J. Phys. Chem. C, 2017, 121, 11281-11289.

[27] Y. Q. Su, I. A. W. Filot, J. X. Liu, E. J. M. Hensen, ACS Catal., 2017, 8, 75-80.

[28] Y. Madier, C. Descorme, A. Le Govic, D. Duprez, J. Phys. Chem. B, 1999, 103, 10999-11006.

[29] J. Liu, B. Liu, Y. Fang, Z. Zhao, Y. Wei, X. Q. Gong, C. Xu, A. Duan, G. Jiang, Environ. Sci. Technol., 2014, 48, 12403-12410.

[30] G. Kresse, J. Hafner, Phys. Rev. B, 1994, 49, 14251.

[31] P. E. Blöchl, Phys. Rev. B, 1994, 50, 17953.

[32] J. P. Perdew, K. Burke, M. Ernzerhof, Phys. Rev. Lett., 1996, 77, 3865 .
[33] S. Dudarev, G. Botton, S. Savrasov, C. Humphreys, A. Sutton, Phys. Rev. $B, 1998,57,1505$.

[34] S. Fabris, S. de Gironcoli, S. Baroni, G. Vicario, G. Balducci, Phys. Rev. $B, \mathbf{2 0 0 5}, 72,237102$.

[35] M. Cococcioni, S. De Gironcoli, Phys. Rev. B, 2005, 71, 035105.

[36] C. Castleton, J. Kullgren, K. Hermansson, J. Chem. Phys., 2007, 127, 244704-244704.

[37] J. L. Da Silva, M. V. Ganduglia-Pirovano, J. Sauer, V. Bayer, G. Kresse, Phys. Rev. B, 2007, 75, 045121.

[38] G. Henkelman, H. Jónsson, J. Chem. Phys., 2000, 113, 9978-9985.

[39] D. Sheppard, R. Terrell, G. Henkelman, J. Chem. Phys., 2008, 128, 134106.

[40] K. Reuter, M. Scheffler, Phys. Rev. B, 2003, 68, 045407.

[41] D. R. Stull, H. Prophet, JANAF thermochemical tables, National Standard Reference Data System, 1971.

[42] L. Nie, D. H. Mei, H. F. Xiong, B. Peng, Z. Ren, X. I. P. Hernandez, A. DeLaRiva, M. Wang, M. H. Engelhard, L. Kovarik, Science, 2017, 358, 1419-1423.

[43] Y. Q. Su, Y. Wang, J. X. Liu, I. A. W. Filot, K. Alexopoulos, L. Zhang, V. Muravev, B. Zijlstra, D. G. Vlachos, E. J. M. Hensen, ACS Catal., 2019, 9, 3289-3297.

[44] E. Slavinskaya, A. Stadnichenko, V. Muravyov, T. Y. Kardash, E. Derevyannikova, V. Zaikovskii, O. Stonkus, I. Lapin, V. Svetlichnyi, A. Boronin, ChemCatChem, 2018, 10, 2232-2247.

[45] T. Y. Kardash, E. A. Derevyannikova, E. M. Slavinskaya, A. I. Stadnichenko, V. A. Maltsev, A. V. Zaikovskii, S. A. Novopashin, A. I. Boronin, K. M. Neyman, Front. Chem., 2019, 7, 114.

[46] A. I. Stadnichenko, V. V. Muravev, S. V. Koscheev, V. I. Zaikovskii, H. A. Aleksandrov, K. M. Neyman, A. I. Boronin, Surf. Sci., 2019, 679, 273-283.

[47] Y. Huang, B. Zhao, X. Hu, S. Lin, R. Ang, W. Song, Y. Sun, Dalton T., 2012, 41, 11176-11186.

[48] L. Zhang, T. Yabu, I. Taniguchi, Mater. Res. Bull., 2009, 44, 707-713.

[49] M. H. N. Assadi, Y. Shigeta, RSC Adv., 2018, 8, 13842-13849.

[50] S. Nakashima, K. Sugioka, K. Midorikawa, K. Mukai, J. Laser Micro. Nanoen., 2014, 9, 132-136.

[51] R. Vuilleumier, M. Sprik, J. Chem. Phys., 2001, 115, 3454-3468.

[52] P. Robkhob, T. S. Herng, J. Ding, I. Tang, S. Thongmee, J. Nanosci. Nanotechno., 2017, 17, 5631-5636.

[53] Y. X. Hu, S. Y. Wu, X. F. Wang, L. L. Li, Defect and Diffusion Forum, Trans Tech Publ, 2009, 71-76.

[54] Y. Q. Su, I. A. W. Filot, J. X. Liu, I. Tranca, E. J. M. Hensen, Chem. Mater., 2016, 28, 5652-5658.

[55] E. V. Matus, L. B. Okhlopkova, O. B. Sukhova, I. Z. Ismagilov, M. A. Kerzhentsev, Z. R. Ismagilov, J. Nanopart. Res., 2019, 21, 11.

[56] O. Laguna, F. R. Sarria, M. Centeno, J. A. Odriozola, J. Catal., 2010, 276, 360-370.

[57] H. Xiong, S. Lin, J. Goetze, P. Pletcher, H. Guo, L. Kovarik, K. Artyushkova, B. M. Weckhuysen, A. K. Datye, Angew. Chem. Int. Ed., 2017, 56, 8986-8991.

[58] S. Hinokuma, H. Fujii, M. Okamoto, K. Ikeue, M. Machida, Chem. Mater., 2010, 22, 6183-6190.

[59] J. S. Elias, N. Artrith, M. Bugnet, L. Giordano, G. A. Botton, A. M. Kolpak, Y. Shao-Horn, ACS Catal., 2016, 6, 1675-1679.

[60] L. Qin, Y. Q. Cui, T. L. Deng, F. H. Wei, X. F. Zhang, ChemPhysChem, 2018, 19, 3346-3349.

[61] W. W. Wang, P. P. Du, S. H. Zou, H. Y. He, R. X. Wang, Z. Jin, S. Shi, Y. Y. Huang, R. Si, Q. S. Song, ACS Catal., 2015, 5, 2088-2099.

[62] J. S. Elias, M. Risch, L. Giordano, A. N. Mansour, Y. Shao-Horn, J. Am. Chem. Soc., 2014, 136, 17193-17200.

[63] L. W. Guo, P. P. Du, X. P. Fu, C. Ma, J. Zeng, R. Si, Y. Y. Huang, C. J. Jia, 
Y. W.Zhang, C. H. Yan, Nature Comm., 2016, 7, 13481.

[64] C. Kalamaras, D. Dionysiou, A. Efstathiou, ACS Catal., 2012, 2, 2729-2742.

[65] X. Yao, J. Cao, L. Chen, K. Kang, Y. Chen, M. Tian, F. Yang, Chin. J. Catal., 2019, 40, 733-743.
[66] M. R. Benjaram, G. Thrimurthulu, L. Katta, Chin. J. Catal., 2011, 32, 800-806.

[67] A. Corma, P. Atienzar, H. Garcia, J. Y. Chane-Ching, Nature Mater., 2004, 3, 394.

[68] Y. Hao, C. K. Yang, S. M. Haile, Chem. Mater., 2014, 26, 6073-6082.

\section{过渡金属掺杂铈中晶格氧的活化}

\section{Ya-Qiong Su, Long Zhang, Valery Muravev, Emiel J. M. Hensen *}

埃因霍温理工大学, 舒伊特催化研究所, 无机材料与催化实验室, P.O. Box 513, $5600 \mathrm{MB}$ 埃因霍温, 荷兰

摘要: 采用密度泛函理论计算研究了在铈表面掺杂的过渡金属(TM)离子对表面晶格氧原子活化的影响. 为此, 测定了经 $\mathrm{TM}$ 离子修饰的 $\mathrm{CeO}_{2}$ 最稳定(111)表面终端的结构和稳定性. 除了保持八面体氧配位的锆和铂掺杂剂外, TM掺杂剂在取代 表面Ce离子时更倾向于正方形平面配位. 除了 $\operatorname{Pt}(1.14 \mathrm{eV})$ 和 $\mathrm{Zr}$ (正方形平面配位不稳定)外, 所有 $\mathrm{TM}$ 掺杂剂的表面结构从八 面体到正方形平面都很容易. 通常, 四价 TM阳离子的离子半径比 $\mathrm{Ce}^{4+}$ 的小得多, 从而导致了显著的拉伸应变晶格, 并解释 了氧空位形成能量的降低. 除Zr外, 当产生一个氧空位时, 优先形成正方形平面结构. 热力学分析表明, $\mathrm{TM}^{\mathrm{a}}$ 杂杂 $\mathrm{CeO}_{2}$ 表面 在典型环境催化条件下存在氧缺陷. 一个具有实际意义的例子是锆掺杂 $\mathrm{CeO}_{2}(111)$ 中的晶格氧容易活化, 从而有利于 $\mathrm{CO}$ 氧 化. 研究结果强调了晶格氧活化的本质和TM掺杂剂在TM-铈固溶催化剂中的优选位置.

关键词: 晶格氧活化; 过渡金属掺杂 $\mathrm{CeO}_{2}(111)$; 密度泛函理论计算; 氧空位; 正方形平面配位; 配位转换; 一氧化碳氧化 收稿日期: 2019-06-28. 接受日期: 2019-07-22. 出版日期: 2020-06-05.

*通讯联系人. 电话: +31-40-2475178; 电子信箱: e.j.m.hensen@tue.nl

本文的电子版全文由Elsevier出版社在ScienceDirect上出版(http://www.sciencedirect.com/science/journal/18722067). 